\title{
Difficulties concerning Diabetes Mellitus Type 1 in children and adolescents
}

\author{
Dificuldades de crianças e adolescentes com Diabetes Mellitus tipo 1 acerca da doença
}

Tatiana Rebouças Moreira ${ }^{1}$, Samila Torquato Araújo Bandeira ${ }^{1}$, Synara Cavalcante Lopes ${ }^{1}$, Silvana Linhares de Carvalho $^{1}$, Francisca Diana da Silva Negreiros ${ }^{1}$, Clarice da Silva Neves ${ }^{1}$

Objective: to evaluate the knowledge on diabetes in children and adolescents and the difficulties regarding the disease. Methods: a quantitative study with 40 patients from 6 to 17 years older who were subjected on a questionnaire based on self-care behaviors proposed by the American Association of Diabetes Educators. Results: the average age was 11.6 years with predominance of the female gender (57.5\%), most attending grade school (80.0\%), naming the parents as primary caregivers (72.5\%). Regarding the knowledge about the disease, the item with the highest percentage of errors was about the pathophysiology of Diabetes Mellitus type 1. On the difficulties related to the treatment, food control and application of insulin had higher frequency. Conclusion: the study revealed a high percentage of correct answers among the participants, suggesting knowledge about the disease. Nevertheless, they reported food control and insulin therapy as the main difficulties related to treatment.

Descriptors: Diabetes Mellitus, Type 1; Medication Adherence; Health Education.

Objetivo: avaliar o conhecimento sobre o diabetes em crianças e adolescentes e as dificuldades acerca da doença. Métodos: estudo quantitativo, com 40 pacientes de 6 a 17 anos que foram submetidos a um questionário, baseado nos comportamentos de autocuidado propostos pela American Association of Diabetes Educators. Resultados: a faixa etária média foi de 11,6 anos, com predominância do sexo feminino $(57,5 \%)$, maioria cursando ensino fundamental $(80,0 \%)$, nomeando os pais como principais cuidadores $(72,5 \%)$. No que diz respeito ao conhecimento acerca da doença, o item com maior percentual de erros foi acerca da fisiopatologia do diabetes mellitus tipo 1. Sobre as dificuldades relacionadas ao tratamento, obtiveram maior frequência: controle da alimentação e aplicação da insulina. Conclusão: o estudo revelou elevado percentual de acertos entre os participantes, sugerindo conhecimento sobre a doença. Apesar disso, estes referiram ser o controle da alimentação e a insulinoterapia as principais dificuldades relacionadas ao tratamento.

Descritores: Diabetes Mellitus Tipo 1; Adesão à Medicação; Educação em Saúde.

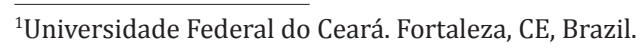




\section{Introduction}

Diabetes Mellitus is configured as a highly prevalent disease, having emerged in epidemic proportions in recent years. One in 11 adults has diabetes, which compromises some $12.0 \%$ of expenses related to health. In Brazil, the prevalence of Diabetes Mellitus is 13.4 to 14.3 million people, representing 9.4 to $9.7 \%$ of the adult population ${ }^{(1)}$.

Among the different types of diabetes, Diabetes Mellitus type 1 is highlighted for representing about 5 to $10.0 \%$ of all types of Diabetes Mellitus, becoming one of the most common chronic diseases of childhood and adolescence, with estimated incidence in Brazil of 7.6 per 100,000 subjects under 15 years of age, which corresponds to about 30,900 children diagnosed ${ }^{(1-2)}$.

Several complications (acute and chronic) are related to Diabetes Mellitus, these are an important public health problem, given the high costs pertaining to prolonged hospitalization and early retirement due to functional disabilities, generating burden on the social security system ${ }^{(3)}$.

A person with Diabetes Mellitus Type 1 will live with the disease for longer periods of time, requiring strict metabolic control involving medication and changes in lifestyle, such as healthy eating and physical activity, in order to prevent and delay the onset of complications related to Diabetes Mellitus ${ }^{(4)}$. However, despite continued advances in knowledge, in therapy and available technology, most people with Diabetes Mellitus type 1 have unsatisfactory glycemic control $^{(5)}$.

In this context, knowledge about the disease is essential, an essential resource for the compliance with the treatment. Thus, it emphasizes the importance of the educational process in multidisciplinary health as one of the key strategies for effective promotion of self-care in diabetic patients, through empowerment, making them participatory subjects of their treatment and able to manage self-care ${ }^{(6-7)}$.

The American Association of Diabetes Educators established seven self-care behaviors and national standards for diabetes education: activity (incorporation of physical activity in lifestyle); healthy eating (incorporation of nutritional management in lifestyle); monitoring (monitor and interpret blood glucose and other parameters, and use the results in decision making); medication (safely use medications for maximum therapeutic effectiveness); Troubleshooting (preventing, detecting and treating acute complications); healthy coping (develop customized strategies to access psychosocial problems) and risk reduction (preventing, detecting and treating chronic complications) ${ }^{(8)}$. These are relevant to have effective self-care management in subjects with diabetes, health professionals should be based on them for the development of education strategies in diabetes ${ }^{(9)}$.

The self-care practices should be encouraged by all health professionals, especially nurses, responsible for the care, dealing with the monitoring of the disease. For such practices, diabetes education is an essential resource and should be composed of activities that facilitate behavior changes and adoption of practices that can reduce the risks of the disease ${ }^{(10-11)}$.

For development of effective educational tools in future studies, it is necessary to characterize the population under study and to identify the main theoretical needs, by the health educator professional, in order to act with the real needs of learning. Thus, this study aimed at assessing the knowledge about diabetes in children and adolescents and the difficulties about the disease.

\section{Methods}

It is a quantitative study made in a pediatric outpatient treatment unit of a university hospital of reference in Ceará, Brazil. The population consisted of 120 patients with Diabetes Mellitus type 1 who underwent assistance at the clinic. The periodicity of medical appointments was once a week, with an average attendance of six patients, with scheduled returns every three months or according to the clinical 
condition of the same. Thus, the study was made with 40 of those patients attending medical appointments or having nursing appointments scheduled during the collection period.

The study presented as inclusion criteria to be from 6 to 17 years old. Exclusion criteria were regarding the ones who missed appointments or the ones who abandoned treatment.

Data collection was made in August, September and October 2014, using a questionnaire containing socio-demographic identification data (age, sex, origin, education, family income, among others), as well as five objective questions each containing four items (right or wrong) on the following topics: pathophysiology of Diabetes Mellitus type 1, insulin, diet, physical activity and hypoglycemia. In addition, a subjective question, in which participants could discuss the difficulties related to the treatment. The questions were designed based on the self-care behavior proposed by the American Association of Diabetes Educators.

The instrument was analyzed by three nurses with experience in the diabetes area, working at the above mentioned hospital, in order to observe possible inconsistencies or difficulties for applicability of the questions, and all observations were accepted.

The questionnaire was applied by the researcher with the study subjects in the presence of the responsible family members, after the nursing or medical appointment and in a private room located at the pediatric clinic, allowing the privacy and anonymity of participants.

The data were imputed and analyzed by the Statistical Package for the Social Sciences version 20.0, which evaluated the measures of central tendency and dispersion, with presentation in tables containing the absolute and relative frequencies.

The study complied with the formal requirements contained in the national and international regulatory standards for research involving human beings.

\section{Results}

The socio-demographic features are shown in Table 1. With respect to gender, $57.5 \%$ (23) were female. Concerning age, the average was 11.6 years. Regarding their origins, 52.5\% (21) lived in Fortaleza, CE, Brazil, while $47.5 \%$ (19) in the countryside of Ceará, Brazil. There was a predominance of those who were enrolled in primary school, with $80.0 \%$ (32).

As for family income, the average was 1.53 minimum wages. The majority, $62.5 \%$ (25), earning up to one minimum wage, while $27.5 \%$ (11) earned from 1.1 to 3 minimum wages and $10.0 \%$ (4) from 3.1 to 7 minimum wages. With regard to caregivers, $72.5 \%$ (29) reported that their parents were the caregivers; $15.0 \%$ (6) stated the grandparents as caregivers, while $12.5 \%$ (5) mentioned other family members.

Table 1 - Socio-demographic features of children and adolescents with Diabetes Mellitus type $1(n=40)$

\begin{tabular}{|c|c|c|c|}
\hline Variables & n (\%) & $\begin{array}{c}\text { Average } \\
\text { (SD) }\end{array}$ & CI (95\%) \\
\hline \multicolumn{4}{|l|}{ Gender } \\
\hline Male & $17(42.5)$ & & $27.18-57.82$ \\
\hline Female & $23(57.5)$ & & $42.18-72.82$ \\
\hline Age range (years) & \multicolumn{3}{|c|}{$11.6 \pm 3.2$} \\
\hline $6-8$ & $10(25.0)$ & & $11.58-38.42$ \\
\hline $9-12$ & $17(42.5)$ & & $27.18-57.82$ \\
\hline $13-17$ & $13(32.5)$ & & $17.98-47.02$ \\
\hline \multicolumn{4}{|l|}{ Origin } \\
\hline Fortaleza & $21(52.5)$ & & $37.02-67.98$ \\
\hline Countryside & $19(47.5)$ & & $32.02-62.98$ \\
\hline \multicolumn{4}{|l|}{ Education } \\
\hline Grade School & $32(80.0)$ & & $67.6-92.4$ \\
\hline High School & $7(17.5)$ & & $5.72-29.28$ \\
\hline University & $1(2.5)$ & & $-2.34-7.34$ \\
\hline \multicolumn{2}{|c|}{ Family income (minimum wages) } & $1.53 \pm 1.22$ & \\
\hline$--\mid 1$ & $25(62.5)$ & & $47.5-77.5$ \\
\hline $1.1|--| 3$ & $11(27.5)$ & & $13.66-41.34$ \\
\hline $3.1|--| 7$ & $4(10.0)$ & & $0.7-19.3$ \\
\hline \multicolumn{4}{|l|}{ Caregivers } \\
\hline Parents & $29(72.5)$ & & $58.66-86.34$ \\
\hline Grandparents & $6(15.0)$ & & $3.93-26.07$ \\
\hline Family members & $5(12.5)$ & & $2.25-22.75$ \\
\hline
\end{tabular}


The average time since diagnosis of Diabetes Mellitus type 1 was 3.26 years. Time longer than assistance time in the pediatric clinic, 2.25 years (Table 2).

Table 2 - Number of children and adolescents with Diabetes Mellitus type 1, according to the time of diagnosis (Dt) and monitoring of the assistance

\begin{tabular}{lccc}
\hline Variables & $\mathbf{n}(\%)$ & Average (SD) & CI (95\%) \\
\hline Time Dt (years) & \multicolumn{3}{c}{$3.26 \pm 3$} \\
$--\mid 1$ & $11(27.5)$ & & $13.66-41.34$ \\
$1-\mid 3$ & $11(27.5)$ & & $13.66-41.34$ \\
$4 \mid--$ & $18(45.0)$ & & $29.58-60.42$ \\
Assistance time (years) & & $2.25 \pm 2.20$ \\
1 & $13(32.5)$ & & $17.98-47.02$ \\
$--|1-| 3$ & $15(37.5)$ & $22.5-52.5$ \\
$4 \mid--$ & $12(30.0)$ & $15.8-44.2$ \\
\hline
\end{tabular}

About the types of insulin, 55.0\% (22) they reported to make use of human insulin (NPH and Regular). Concerning the application of insulin, $62.5 \%$ (25) showed themselves to be responsible for the application. When confronted to the performance of blood glucose monitoring, the majority, 97.5\% (39), said their average daily glucoses monitoring was 4.4 (Table 3).

Table 3 - Number of children and adolescents with Diabetes Mellitus type 1, according to insulin and glucose monitoring

\begin{tabular}{|c|c|c|c|c|c|c|}
\hline Variables & n (\%) & Average & CI $(95 \%)$ & \multirow{3}{*}{\multicolumn{3}{|c|}{$\begin{array}{l}\text { Table } 5 \text { - Distribution of the answers given by } \\
\text { children and adolescents as the difficulties related to } \\
\text { the treatment of Diabetes Mellitus Type } 1\end{array}$}} \\
\hline \multicolumn{4}{|l|}{ Types of insulin } & & & \\
\hline Human (NPH/R) & $22(55.0)$ & & $39.58-70.42$ & & & \\
\hline & $18(45.0)$ & & $29.58-60.42$ & Variable & n (\%) & CI $(95 \%)$ \\
\hline $\begin{array}{l}\text { Insulin application } \\
\text { Patients }\end{array}$ & $25(62.5)$ & & $47.5-77.5$ & Difficulties & & \\
\hline $\begin{array}{l}\text { Caregivers } \\
\text { Glucose monitoring }\end{array}$ & $15(37.5)$ & & $22.5-52.5$ & Insulin application & $21(52.5)$ & $37.02-67.98$ \\
\hline Yes & $39(97.5)$ & & $92.66-102.34$ & Glucose monitoring & $16(40.0)$ & $24.82-55.18$ \\
\hline No & $1(2.5)$ & & $0-7.34$ & & & \\
\hline Frequency of daily monitoring & & $4.4 x /$ day & & Food Control & $22(55.0)$ & $39.58-70.42$ \\
\hline$-\mid 2$ & $6(15.0)$ & & $3.93-26.07$ & Practice of exercises & $6(15.0)$ & $3.93-26.07$ \\
\hline $3|--| 4$ & $21(52.5)$ & & $37.02-67.98$ & & & \\
\hline $5|-| 8$ & $13(32.5)$ & & $17.98-47.02$ & Control of hypoglycemia & $9(22.5)$ & $9.56-35.44$ \\
\hline
\end{tabular}

Concerning the difficulties of knowledge about the disease, within the five objective multiple choice questions, the percentage of correct answers was $84.0 \%$ and the question which addressed the pathophysiology of Diabetes Mellitus type 1 was the one with the lowest percentage of correct answers (67.5\%) (Table 4).

Table 4 - Distribution of the answers given by children and adolescents concerning the knowledge of Diabetes Mellitus type 1

\begin{tabular}{lcccc}
\hline Variables & $\begin{array}{c}\text { No errors } \\
\mathbf{n ( \% )}\end{array}$ & $\begin{array}{c}\text { Errors } \\
\mathbf{n ( \% )}\end{array}$ & $\begin{array}{c}\text { CI (95\%) No } \\
\text { errors }\end{array}$ & $\begin{array}{c}\text { CI (95\%) } \\
\text { Error }\end{array}$ \\
\hline Q1. Pathophysiology & $27(67.5)$ & $13(32.5)$ & $52.98-82.02$ & $17.98-47.02$ \\
Q2. Insulin therapy & $33(82.5)$ & $7(17.5)$ & $70.72-94.28$ & $5.72-29.28$ \\
Q3. Food supply & $38(95.0)$ & $2(5.0)$ & $88.25-101.75$ & $-1.75-11.75$ \\
Q4. Physical Activity & $37(92.5)$ & $3(7.5)$ & $84.34-100.66$ & $-0.66-15.66$ \\
Q5. Hypoglycemia & $33(82.5)$ & $7(17.5)$ & $70.72-94.28$ & $5.72-29.28$ \\
Total & $168(84 \%)$ & $32(16 \%)$ & $72.64-95.36$ & $4.64-27.36$ \\
Average (SD) & $33.6 \pm 4.34$ & $6.4 \pm 4.34$ & & \\
\hline
\end{tabular}

Regarding the difficulties during treatment, the most frequently items listed were the feed control $(55.0 \%)$ and insulin therapy $(52.5 \%)$, as shown in Table 5.

Table 5 - Distribution of the answers given by children and adolescents as the difficulties related to the treatment of Diabetes Mellitus Type 1 


\section{Discussion}

Throughout the study, some limitations appeared. Among them, there is the short collection period and the small number of participants, because of the frequency of returns, which occurred mostly quarterly interfering with the sample size. The study, however, acts as a support for future research with more refined methodological design, that broadens the discussion about knowledge and the difficulties of patients with Diabetes Mellitus type 1, allowing assistance strategy in line with the real needs of users.

Nevertheless, the findings of this research are important for professional practice in the health education process, as help in building an effective care plan, directed to the main demands of the population, enabling the skilled care for the empowerment of individuals in search of adhesion to treatment, in order to optimize the control and prevent complications related to the disease.

As for the socio-demographic characterization of the present study, there was a slight female predominance $(57.5 \%)$. Corroborating the finding, it is emphasized that in some studies of people with Diabetes Mellitus, shown in their socio-demographic features, there was a greater predominance of women $^{(12-13)}$, while international prevalence studies, which analyzed samples of a larger population, did not show significant variation of sex among people with Diabetes Mellitus type $1^{(14)}$.

Concerning their origin, there was equivalence of patients from the capital and from the countryside, which is justified, in part, by the fact that the institution in question is a reference unit in endocrinology throughout the state, there is a great demand for referrals from the countryside, where often there is a lack of infrastructure and skilled professionals for the safe management of the pathology in question ${ }^{(10)}$.

Regarding education, the majority $(80.0 \%)$ were in elementary school, this finding is justified by the age of children and adolescents studied. However, research conducted with adults with Diabetes Mellitus demonstrate the predominance of few years of study by part of the population ${ }^{(15)}$ and there may be impairment in the incorporation of selfcare behaviors, since the low education may hinder access to information and thus adhesion to treatment. Therefore, schooling is emphasized, as a factor to be considered in proposing educational strategies ${ }^{(16)}$.

Regarding the family income, the average of 1.53 minimum wages showed the low purchasing power of the population in question and their families. Sociodemographic studies of populations with chronic diseases have shown that part of the population with lower purchasing power has more difficult access to health services, with great damage to the control of the disease $\mathrm{e}^{(17)}$.

This situation is justified, in part, because the unfavorable socio-economic condition of the user is fully anchored to the public health network services, which often lack drugs and supplies in satisfactory amount to maintain treatment without damage, and a great demand for specialized services, committing often jeopardizing, the ideal period for reassessments and return medical appointments. Thus, the role of the State as the Unified Health System becomes essential to guarantee all the support of necessary measures in order to have a greater adhesion to the treatment ${ }^{(10)}$.

The parents were identified as the main caregivers. Concerning age, the average age of the population was 11.6 years. It is noteworthy that the majority (62.5\%) was already responsible for the administration of insulin, legitimizing studies that indicate the transference of responsibility from the parents to their children, the self-administration of insulin occurs from to 10 to 12 years of age ${ }^{(18)}$.

Concerning the types of insulin in use, the majority $(55.0 \%)$ used human insulin (NPH and regular) as standard therapy, justifying its significant use due to the free distribution by the Unified Health 
System. The average of glucose monitoring performed by patients was 4.4 times per day. The blood glucose monitoring as is essential to the metabolic control of patients with Diabetes Mellitus type 1 and it always be guided and encouraged by the health professional educators $^{(4)}$.

Regarding the questions that assessed knowledge on Diabetes Mellitus type 1, the average percentage of correct answers was $84.0 \%$, the question addressing the pathophysiology issue of the disease presented the highest error rate (32.5\%). These patients were assisted in a referral hospital in endocrinology, having been covered by a health education process, either individually or in groups, at some time of the clinical assistance. Therefore, it is noteworthy that access to health-related information may not occur in the same proportions for the population in general. Thus, studies with more elaborate methodological designs are needed, confirming or amending these findings in a larger perspective.

Another point to be addressed is that the lack of knowledge of the pathophysiology of the disease can interfere directly or indirectly in all the therapeutic and adhesion process. Understanding the etiology of the disease, its signs and symptoms, treatment modalities and acute and chronic complications related to this disorder can act as a key link in the adhesion process $^{(19)}$.

There was a high rate of correct answers on issues related to insulin therapy $(82.5 \%)$ and healthy eating (95.0\%), but these were also the main difficulties identified with regard to the treatment of Diabetes Mellitus type 1 patients, suggesting a gap between having the knowledge about diabetes and manage to apply it in daily practice.

Because of the complexity of factors involved in diabetes, the acquisition of knowledge related to the disease, essential for the adhesion to the treatment, should be added to a set of skills to be developed, so interdisciplinary health support which help in this process is indispensable ${ }^{(20)}$.

Thus, the results suggest that to know the people with whom you work and identify the needs of this disease is related to the first and fundamental step for the performance of effective educational strategies. In addition, a sine qua non condition is to understand the patient with Diabetes Mellitus type 1 in a holistic way, seeing him as the subject of the treatment, establishing priorities in the adhesion process and seeking interdisciplinary care, in order to have the highest quality treatment that helps in the prevention and/or delay of complications related to the disease.

\section{Conclusion}

The study revealed a high percentage of correct answers among participants, suggesting knowledge about the disease. Nevertheless, they often reported that the control of food and insulin therapy are the main difficulties related to treatment.

It is essential to consider the knowledge, difficulties and individual needs related to the disease in order to have effective performance of health professionals in the health education process, seeking the empowerment of subjects to have effective adhesion to the treatment, with full implementation of self-care.

\section{Collaborations}

Moreira TR contributed in the design, analysis, data interpretation, article writing and final approval of the version to be published. Bandeira STA, Lopes SC, Carvalho SL, Negreiros FDS and Neves CS contributed to the relevant critical review of the intellectual content, article writing and final approval of the version to be published. 


\section{References}

1. International Diabetes Federation. IDF Diabetes Atlas. Brussels/Belgium: International Diabetes Federation; 2015.

2. Sociedade Brasileira de Diabetes. Diretrizes. Tratamento e acompanhamento do Diabetes Mellitus. São Paulo: Sociedade Brasileira de Diabetes; 2015.

3. Flor LS, Campos MR, Oliveira AF, Schramm JMA. Diabetes burden in Brasil: fraction attributable to overweight, obesity and excess weight. Rev Saúde Pública. 2015; 49(29):29-3.

4. Felicio SJ, Sousa ACCB, Koury CC, Abrahão Neto JF, Miléo KB, Santos FM, et al. Health-related quality of life in patients with type 1 diabetes mellitus in the different geographical regions of Brazil: data from the Brazilian Type 1 Diabetes Study Group. Diabetol Metab Syndr [Internet]. 2015 [cited 2016 Jun 13]; 7:87. Available from: http://www.ncbi. nlm.nih.gov/pmc/articles/PMC4596564/

5. Leite EB, Pedrosa HC, Casulari LA. Results of glycated hemoglobin during treatment with insulin analogues dispensed in the public health system of Federal District in Brazil. Diabetol Metab Syndr [Internet]. 2015 [cited 2016 Jun 13]; 7:66. Available from: https://www.ncbi.nlm.nih. gov/pmc/articles/PMC4539715/

6. Grossi SAA, Pascali PM. Cuidados de enfermagem em Diabetes Mellitus. São Paulo: Sociedade Brasileira de Diabetes. A. C. Farmacêutica; 2011.

7. Dorchy H. One center in Brussels has consistently had the lowest HbA1c values in the 4 studies (1994-2009) by the Hvidoere International Study Group on Childhood Diabetes: What are the "recipes"? World J Diabetes. 2015; 6(1):1-7.

8. American Association of Diabetes Educators. Diabetes education curriculum: a guide to successful self-management. Quick Overview. Chicago: AADE; 2015.
9. Haas P, Maryniuk M, Beck J, Cox CE, Duker P, Edwards L, et al. National standards for diabetes self-management education and support. Diabetes Care. 2012; 35(11):2393-401.

10. Rubin O, Azzolin K, Muller S. Adesão ao tratamento de Diabetes Mellitus tipo 1 atendidos em um programa especializado em Porto Alegre. Medicina. 2011; 44(4):367-76.

11. Ren M, Yang C, Lin DZ, Xiao HS, Mai LF, Guo YC, et al. Effect of intensive nursing education on the prevention of diabetic foot ulceration among patients with high-risk diabetic foot: a follow-up analysis. Diabetes Technol Ther. 2014; 16(9):57681.

12. Almeida-Pititto B, Dias ML, Moraes ACF, Ferreira SRG, Franco DR, Eliaschewitz FG. Type 2 diabetes in Brazil: epidemiology and management. Diabetes Metab Syndr Obes [Internet]. 2015[cited 2016 Jun 13]; 8:17-28. Available from: https://www.ncbi. nlm.nih.gov/pmc/articles/PMC4298341/

13. Bertoldi AD, Kanavos P, França GVA, Carraro A, Tejada CAO, Hallal PC, et al. Epidemiology, management, complications and costs associated with type 2 diabetes in Brazil: a comprehensive literature review. Global Health [Internet]. 2013 [cited 2016 Jun 13]; 9:62. Available from: http:// globalizationandhealth.biomed central.com/ articles/10.1186/1744-8603-9-62

14. El-Ziny MAE, Salem NAB, El-Hawary AK, Chalaby NM, Elsharkawy AAE. Epidemiology of childhood type 1 diabetes mellitus in Nile Delta, Northern Egypt - a retrospective study. J Clin Res Pediatr Endocrinol. 2014; 6(1):9-15.

15. Coelho ACM, Villas Boas LCG, Gomides DS, FossFreitas MC, Pace AE. Self-care activities and their relationship to metabolic and clinical control of people with diabetes Mellitus. Texto Contexto Enferm. 2015; 24(3):697-705.

16. Oliveira KC, Zanetti ML. Knowledge and attitudes of patients with diabetes mellitus in a primary health care system. Rev Esc Enferm USP. 2011; 45(4):862-8. 
17. Rodriguez MTG, Santos LC, Lopes ACS. Adesão ao aconselhamento nutricional para o diabetes mellitus em serviço de atenção primária à saúde. Rev Min Enferm. 2014; 18(3):685-90.

18. Sparapani VC, Borges ALV, Dantas IRO, Pan R, Nascimento LC. Children with Type 1 Diabetes Mellitus and their friends: the influence of this interaction in the management of the disease. Rev Latino-Am Enfermagem. 2012; 20(1):117-25.
19. Braga TMS, Bomfim DP, Filho DS. Special Needs of Students With Diabetes Mellitus Type 1 Identified by Relatives. Rev Bras Educ Espec. 2012; 18(3):431-48.

20. Teixeira CRS, Becker TAC, Citro R, Zanetti ML, Landim CAP. Validation of nursing interventions in people with diabetes mellitus. Rev Esc Enferm USP. 2011; 45(1):173-9. 